\title{
DISTRIBUIÇÃO ESPAÇO-TEMPORAL DO CAMARÃO XIPHOPENAEUS KROYERI (HELLER, 1862) (DECAPODA: DENDROBRANCHIATA) NA PLATAFORMA CONTINENTAL DO ESTADO DE SERGIPE
}

\author{
Santos, R.C. ${ }^{1,2, *}$; Costa, R.C. ${ }^{1}$ \& Hirose, G.L. ${ }^{2}$ \\ ${ }^{1}$ Universidade Estadual Paulista (UNESP), Faculdade de Ciências Bauru. Laboratório de Biologia de Camarões \\ Marinhos e de Água doce (LABCAM). \\ ${ }^{2}$ Universidade Federal de Sergipe (UFS), Campus São Cristóvão. Laboratório de Carcinologia. \\ *Corresponding author: rafa_bio@hotmail.com.br
}

\begin{abstract}
Xiphopenaeus kroyeri (Heller, 1862) se destaca como grande recurso pesqueiro do Brasil. Apesar de sua importância econômica, $X$. kroyeri vem sofrendo grande impacto gerado pelas praticas pesqueiras, podendo estar considerado como sobreexplotado, ou moderadamente explotado, a depender da região. O presente estudo avaliou a abundância e a distribuição espaço-temporal de $X$. kroyeri no estado de Sergipe, afim de auxiliar a utilização das populações de camarões de maneira sustentável. As amostras foram realizadas mensalmente de setembro/2013 a agosto/2014 por meio de um barco camaroneiro equipado com redes "double rig" nas profundidades de 5, 15 e 30m, sendo realizados três arrastos de $15 \mathrm{~min}$ em cada profundidade por mês. Em cada ponto também foram registradas variáveis abióticas. Em laboratório, os indivíduos foram identificados quanto ao sexo e mensurados quanto o comprimento da carapaça $(\mathrm{CC} \mathrm{mm})$. Os resultados obtidos foram analisados entre os meses, estações e profundidades. Quanto aos fatores ambientais, foram encontradas diferenças temporais apenas para fatores hidrológicos $(\mathrm{p}<0,01)$ e para o espaço, apenas para salinidade de fundo e textura do sedimento $(p<0,05 ; p<0,01)$. Foi estimado um total de 56350 camarões, dos quais foram mensurados 6418 indivíduos (3457 fêmeas e 2961 machos). Variações significativas foram encontradas na distribuição temporal e espacial $(\mathrm{p}<0,01)$ dos camarões, com as maiores abundâncias encontradas nos meses de setembro/2013 ( $\mathrm{n}=9475)$ e julho/2014 ( $n=8811)$ e nos $5 \mathrm{~m}(\mathrm{n}=20353)$ e $15 \mathrm{~m}(\mathrm{n}=27662)$ de profundidade. A distribuição temporal dos indivíduos ocorreu devido às relações dos ciclos sazonais de chuvas e seu ciclo de vida, com a abundância coincidindo com picos de precipitação. O alto volume de chuvas contribui para uma maior descarga de água doce na região costeira, gerando aumentos no aporte de nutrientes proveniente de águas continentais, podendo contribuir para o acréscimo na abundância. Em relação ao espaço, diferenças foram explicadas devido às características do sedimento, com X. kroyeri associados a grãos finos, considerado um aspecto comum em peneídeos por facilitar o comportamento de bioturbação e preservando energia. Os resultados obtidos sobre a abundância e a distribuição reforçam a importância da obtenção de dados representativos dos aspectos ecológicos de camarões da família Penaeidae, fornecendo subsídios para uma área de defeso adequado para preservação do estoque pesqueiro destes animais.
\end{abstract}

Palavras-chave: abundância, Penaeidae, pesca.

Financiamento: CAPES; CNPq: \#482802/2012-0; FAPESP: \#2018/00739-0. 